\title{
Enhancement of stability margin based on dynamic brake strategy
}

\author{
Majli Nema Hawas \\ Department of Electrical Power Engineering, Electrical Engineering Technical College, Iraq
}

\begin{tabular}{l} 
Article Info \\
\hline Article history: \\
Received Oct 15, 2018 \\
Revised Jan 18, 2019 \\
Accepted Feb 28, 2019 \\
\hline
\end{tabular}

\section{Keywords:}

Angular velocity

Dynamic braking

Rate change of kinetic energy

Transient stability

Transient stability margin

\begin{abstract}
The Rate of Change Kinetic Energy (RACKE) method achieves considerable reduction in computing time by virtue of the way that it does not need the solution of system equation beyond fault clearing time. In RACKE method the machine which tends to lose synchronism can be defined as that which has the largest negation RACKE value. The injection of the brake ought to be achieved when RACKE of the machine liable to be unstable reaches its maximum negative value. Elimination happens when RACKE of the machine is zero and disturbance angular velocity passes through zero changing sign from positive to negative. To defining the instant of injection and elimination of brake, RACKE method can be used to investigate the transient stability margin of a power system through evaluation of RACKE value at the instant of fault clearance. The simulation demonstrates that the applying of a braking resistor at the terminal of each of the machines, pulling of synchronism, simultaneously brings the system into stable trajectory. It is clear from the results obtained that dynamic braking depending on the RACKE criterion for insertion and removal of the brake gives excellent results in an enhancement of transient stability margin.
\end{abstract}

Copyright $\odot 2019$ Institute of Advanced Engineering and Science. All rights reserved.

\section{Corresponding Author:}

\author{
Majli Nema Hawas, \\ Department of Electrical Power Engineering, \\ Electrical Engineering Technical College, \\ Middle Technical University, \\ Baghdad, Iraq. \\ Email: gnmajli@gmail.com
}

\section{INTRODUCTION}

Transient stability is formulated to determine the maximum time that a disturbance may be allowed to remain without losing synchronism. This time is called the Critical Clearing Time CCT of the power system. The application of a braking resistor can be effective in the reduction of acceleration torque and improving stability conditions [1-3]. The prediction of system stability can be obtained either by using classical or direct approaches. Direct methods offer themselves as good tools for fast assessment of system stability. In these methods, the classical approach is used partially and the stability of power system is determined using the energy balance in the system [4-6]. The dynamic braking is applied to a single machine connected to infinite bus as well as to multi-machine system. The results of the application of dynamic to single and multi-machine test system are obtained. A comparison between CCT with and without braking as predicted by RACKE method is presented [7-9]. The MATLAB/Simulink design considerations of the single and multi-machine presented and discussed along with obtained results. The remainder of this paper is organized as follows. Section 2 describes the design of braking resistor. Section 3 describes the strategies for a dynamic braking with RACKE criteria. System modeling is presented in Section 4. Simulation application procedures are presented in Section 5. The discussion of obtain results are then presented in Section 6. In Section 7 the conclusions are presented. 


\section{DESIGN OF BRAKING RESISTOR}

The dynamic brake shunted between generator terminals and earth to dissipate the excess kinetic energy gained during fault-on period.Tables and Figures are presented center, as shown below and cited in the manuscript [10].

\subsection{Injection and elimination of the brake strategies}

Injection, elimination, and size of the brake are the most important factors affecting stability margins. Accurate timing of Insertion, removal, and size of the brake leads to better damping of swings caused by a disturbance [11], [12].

I. Brake injection:

Injection strategies followed by other authors can be summarized as follows:

a) Speed deviation is used to decide brake insertion. Rate of change of frequency and difference between mechanical input and electrical output may be used in conjunction with speed deviation to decide time of insertion of the brake when a severe disturbance occurs only [13].

b) Clearing of fault can be used to decide the time at which the braking resistor should be inserted. The braking resistor should be inserted, as early as possible before the fault clearance so that the increase in decelerating power caused by the application of dynamic braking is obtain as early as possible [14].

c) The depression in the electrical output power and machine terminal voltage is used to decide insertion of the brake. [15]

d) The disturbance velocity in conjunction with angular to decide insertion of braking resistance. [16].

e) The disturbance angular velocity in conjunction with rotor angle can be used to establish the stability zone for a power system [17].

II. Brake removal

Removal strategies used by previous authors might be summarized as pursues:

a) Angular velocity of the faulted machine can be used as a guide to decide removal of the brake. [15].

b) An optimum value for injection duration which gives the maximum possible reduction in the rotor swing amplitudes. [18]

c) An angular acceleration in addition to angular velocity can be used to decide removed of the brake [8].

$$
r<\omega<-r \text { and } \hat{\mathrm{W}}<0
$$

d) In an interconnected power system, the angular velocity of a faulted area can be us as a guide to decide elimination of the brake [19].

e) A stable zone for a power system must be evaluated empirically and the brake should be eliminated when, [20].

$0<\omega<\omega^{\prime}$ and $\hat{\mathrm{w}}<0$

As elimination of the brake is affected at a certain definite time by RACKE, it overcomes most of the disadvantages of the method used previously, thus the RACKE method have been used to decide elimination of the brake.

\subsection{Size of the brake:}

The size of the brake ought to be with the end goal that it retains a power of 0.7-0.8 of generation at a power station [21]. Size of the brake could be evaluated, to such an extent that it ingests a certain measure of power according to rate machine capacity, i.e. five percent of the rated machine capacity [22]. As shown in (3) gives the relationship between the output power of the generator and the size of the brake given in references.

$$
P_{(R b)}=\frac{X V E \sin \delta R_{b}^{2}+X_{1}^{2} E^{2}+\left(X_{1} X-X_{1}^{2}\right) V_{b} E \cos \delta R_{b}}{\left(X^{2} R_{b}^{2}\right)+\left(X^{2} X_{1}^{2}-2 X X_{1}^{3}-X_{1}^{4}\right)}
$$

The dynamics of the faulted machine in a multi-machine power system during braking can be represented by the following expression,

$$
P_{(R b)_{i}}=\frac{X V E_{i} \sin \delta_{i} R_{b_{i}}^{2}+X_{1}^{2} E_{i}{ }^{2}+\left(X_{1} X-X_{1}^{2}\right) V_{b} E_{i} \cos \delta_{i} R_{b_{i}}}{\left(X^{2} R_{b_{i}}^{2}\right)+\left(X^{2} X_{1}^{2}-2 X X_{1}^{3}-X_{1}^{4}\right)}
$$


From (4), the size of the brake could be evaluated for a certain value of power of machine (i) Thus the equivalent admittance of the system obtained through reduced matrix technique is used to evaluate the braking resistor necessary to determine the new transient stability limit of the power system [19].

\section{STRATEGIES FOR DYNAMIC BRAKING WITH RACKE CRITERIA}

At any instant of time, the instantaneous value of RACKE (IRACKE) can be obtained from [23, 24]:

$$
\begin{aligned}
& \operatorname{IRACKE}(t)=M \frac{\omega_{(\mathrm{t})}}{\omega_{\mathrm{s}}} \frac{\mathrm{d} \omega}{\mathrm{dt}} \\
& \operatorname{IRACKE}(t c)=\frac{p_{m} t_{c}}{M \omega_{\mathrm{s}}}\left[p_{m}-p_{\text {max }} \sin \left(\delta_{o}+\frac{p_{m} t_{c}^{2}}{2 M}\right)\right] \\
& \left.R A C K E\right|_{t=t_{c}}=\frac{p_{m}^{2}}{M \omega_{\mathrm{s}}} t-\left.\frac{p_{m} p_{\max }}{M \omega_{\mathrm{s}}} \sin \delta_{1}\right|_{t=t_{c}} \\
& \frac{\left.R A C K E\right|_{t=t_{c}}}{\mathrm{dt}}=\frac{p_{m}^{2}}{M \omega_{\mathrm{s}}} t-\left.\frac{p_{m} p_{\max }}{M \omega_{\mathrm{s}}} \sin \delta_{1}\right|_{t=t_{c}}-\left.\frac{p_{m} p_{\max }}{M \omega_{\mathrm{s}}} t \frac{\mathrm{d} \delta_{1}}{\mathrm{dt}} \cos \delta_{1}\right|_{t=t_{c}}
\end{aligned}
$$

The brake should be removed when this RACKE passes through zero. Figure 1 shows RACKE against time for stable operation. The brake should be inserted at point BI and removed when RACKE passes through zero, point BR in the figure. [24, 25].

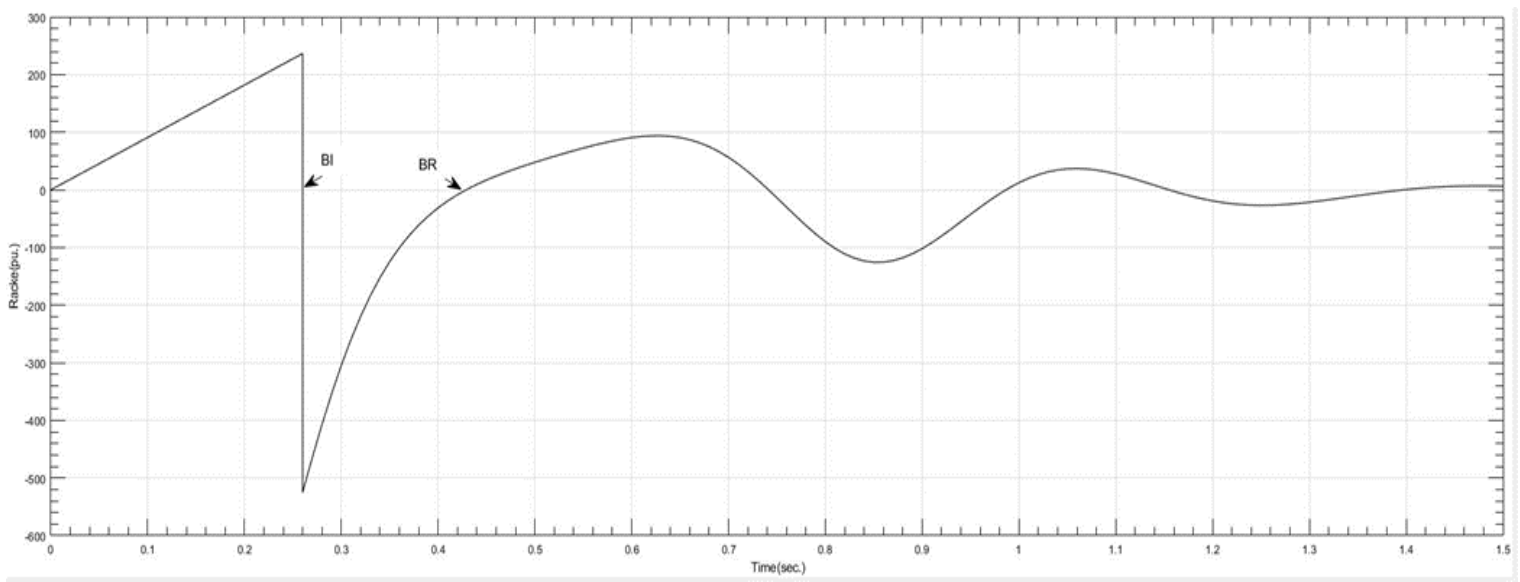

Figure 1. RACKE against time for power system (S1), FCT=260 msec. without brake, critical stable case

\section{TEST SYSTEMS}

The first case study system is shown in Figure 2a below which consists of one synchronous generator connected to an infinite bus by a short transmission line with re and Xe. The second case study is shown in Figure 2b which consists of 3 synchronous generators, 9 buses, and 6 transmission lines [12].

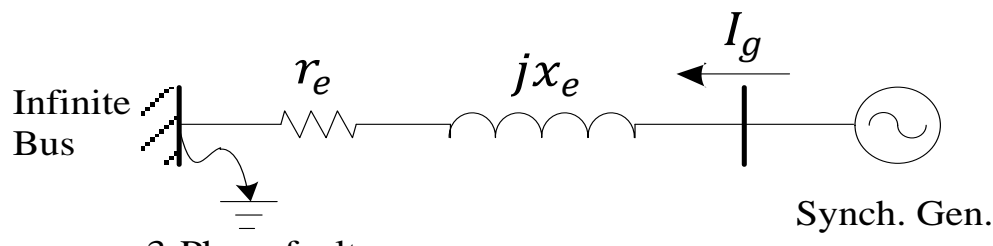

3-Phase fault

Figure 2a. Synchronous generator connected to infinite bus 


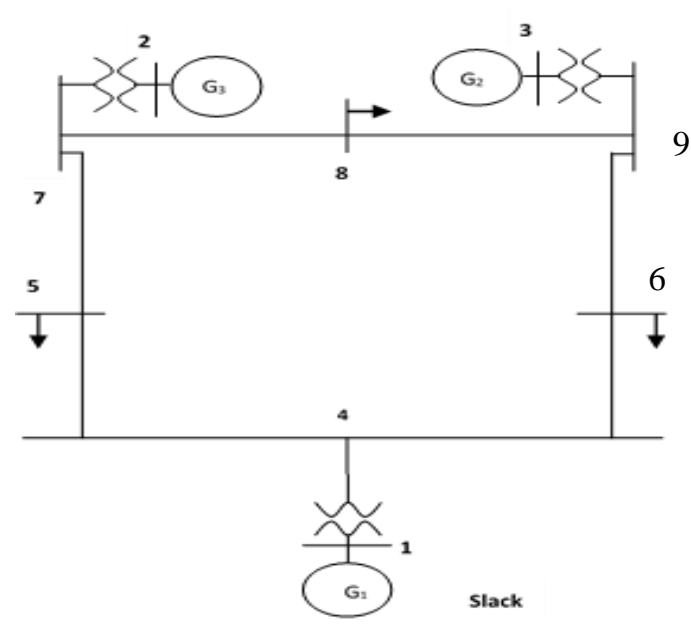

Figure 2b. IEEE 9-bus power system

\section{APPLICATION OF THE TEST SYSTEMS WITH DYNAMIC BRAKE}

This case represents the implementation of the proposed dynamic brake on test systems shown in Figure 3 with brake controller.

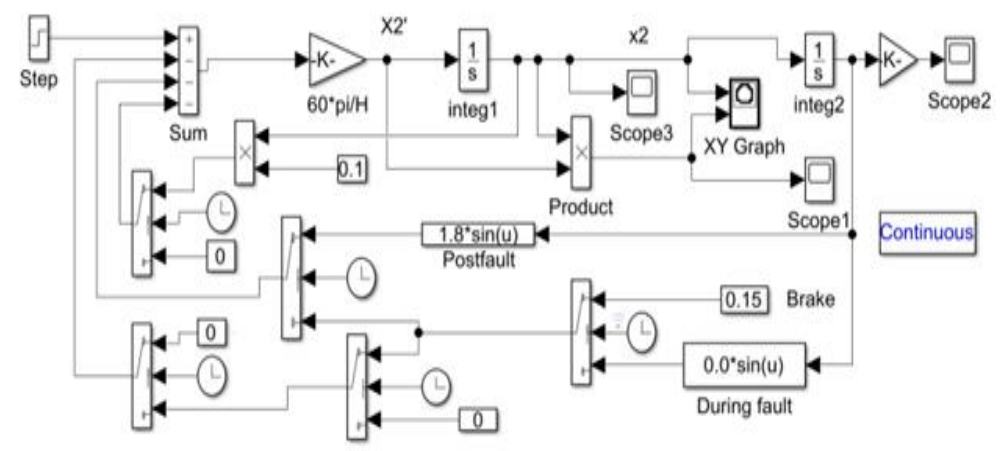

Figure 3a. Simulink model for transient study of single machine power system

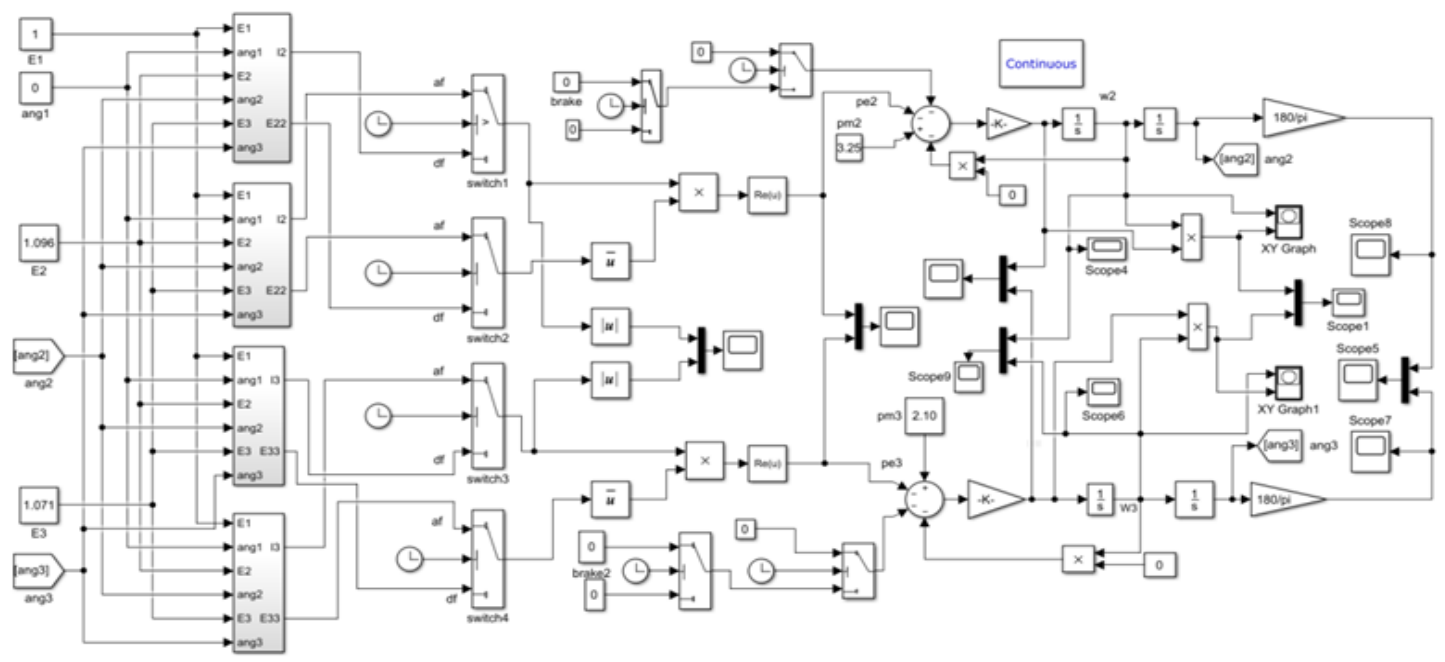

Figure 3b. Simulink model for transient stability study (multi-machine power system) 


\section{RESULTS AND DISCUSSION}

The injection of braking resistor leads to an increase in the CCT of the power system. According to the strategy followed by RACKE method the times of brake insertion and removal for the test power systems $\mathrm{S} 1$ and $\mathrm{S} 2$ are as shown in Table 1.

Table 1. The times of Brake Insertion and Removal for the Test Power Systems S1 and S2

\begin{tabular}{lllllll}
\hline Power system & $\begin{array}{l}\text { Time of BI } \\
\text { msec. }\end{array}$ & $\begin{array}{l}\text { Time of BR } \\
\text { msec. }\end{array}$ & $\begin{array}{l}\text { CCT } \\
\text { msec. }\end{array}$ & $\begin{array}{l}\text { FCT } \\
\text { msec. }\end{array}$ & $\begin{array}{l}\text { \% Increase } \\
\text { of CCT }\end{array}$ & State \\
\hline S1 & 250 & 500 & 250 & 280 & 12 & stable \\
S2 & 200 & 380 & 200 & 240 & 20 & stable \\
\hline
\end{tabular}

\subsection{Test system $S 1$}

RACKE method showed that RACKE of the machine reach its maximum negative value at 250 msec. i.e. the critical clearing time of the system $(250 \mathrm{msec}$.). Figure $4 \mathrm{a}$ shows the rotor angle against time for power system S1 at fault clearing time FCT $(240 \mathrm{msec}$.), stable state, without brake. Figure $4 \mathrm{~b}$ shows the rotor angle against time for power system S1 at CCT $(250 \mathrm{msec}$.), critical stable state, without brake. For the system S1 the fault is cleared at $280 \mathrm{msec}$. this lead to unstable transient response of the power system in the absence of braking resistor. Figure $4 \mathrm{c}$ shows the rotor angle against time for power system S1 at FCT (280 msec.), stable state, with optimum size of the brake, as calculated from (3) for single machine and from (4) for multi machine. The CCT of the power system $(250 \mathrm{msec}$.) is taken to be the time at the insertion of the brake should occur. Figures 4e and 4.f are a plot of RACKE versus disturbance angular velocity. Removal of the brake must be achieved when RACKE of the machine equal zero, at FCT=250 msec.

\subsection{Test system S2}

Figure (5) shows the results obtained for the power system S2 according the RACKE method of insertion and removal of the brake. It could be seen from Figures ( 4 and 5) that the oscillation is best damped. The advantages of the RACKE method strategy it indicates the accurate timing for insertion and removal of the brake leads to large CCT and better stability margin of the power system.

The new critical clearing time of the power systems S1 and S2 with brake resistor for the RACKE method is $280 \mathrm{msec}$. and $240 \mathrm{msec}$, that mean the stability margin enhancement with percentage $12 \%$ for single machine power system and $20 \%$ for multimachine power system respectively.

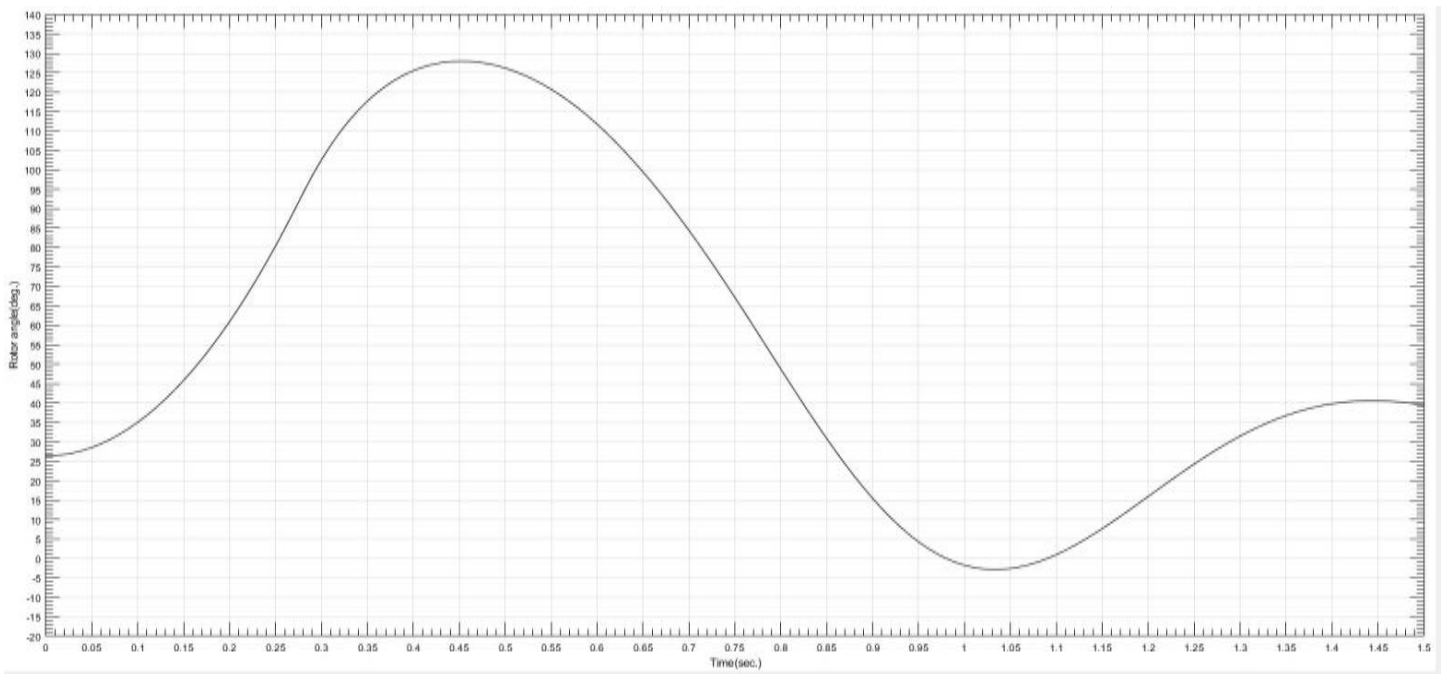

Figure 4a. Determination of TCC for power system (S1) at $240 \mathrm{msec}$. fault clearing (critical stable) 


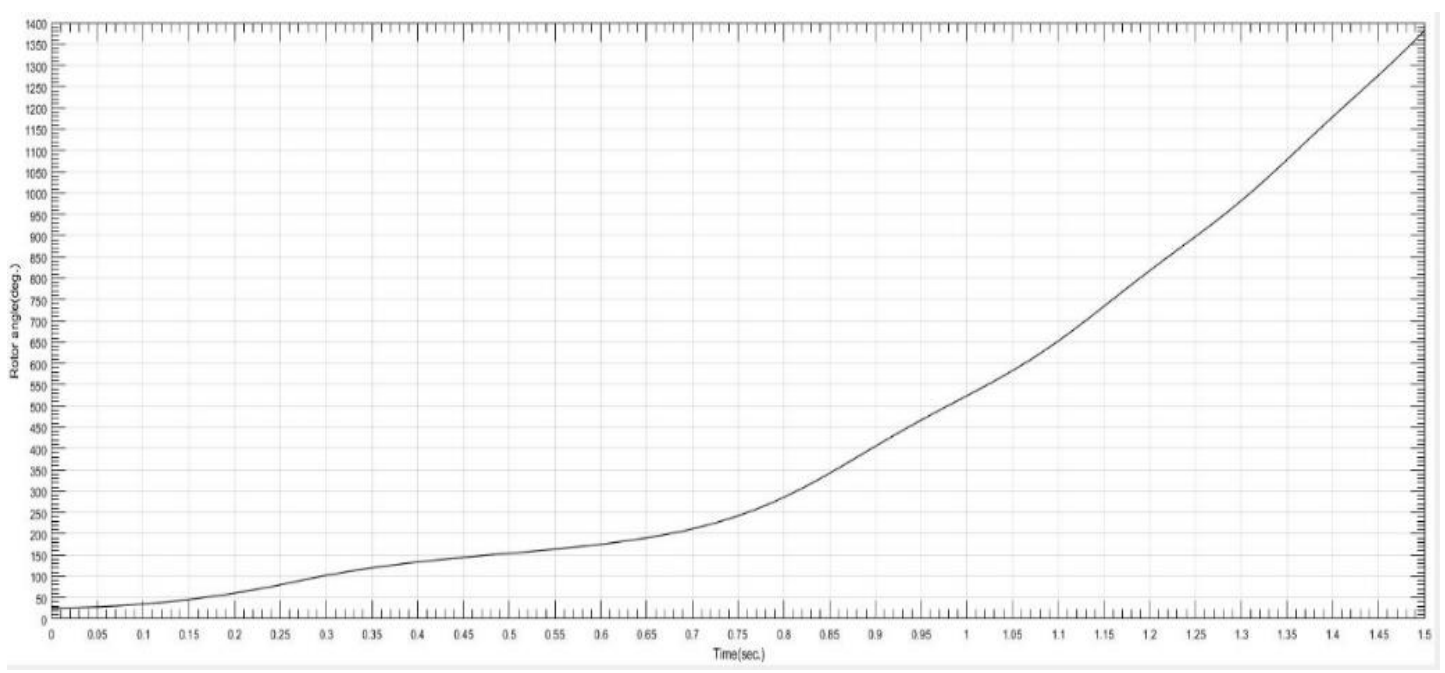

Figure 4b. Swing curve for power system (S1) at $245 \mathrm{msec}$. fault clearing, (unstable) without brake

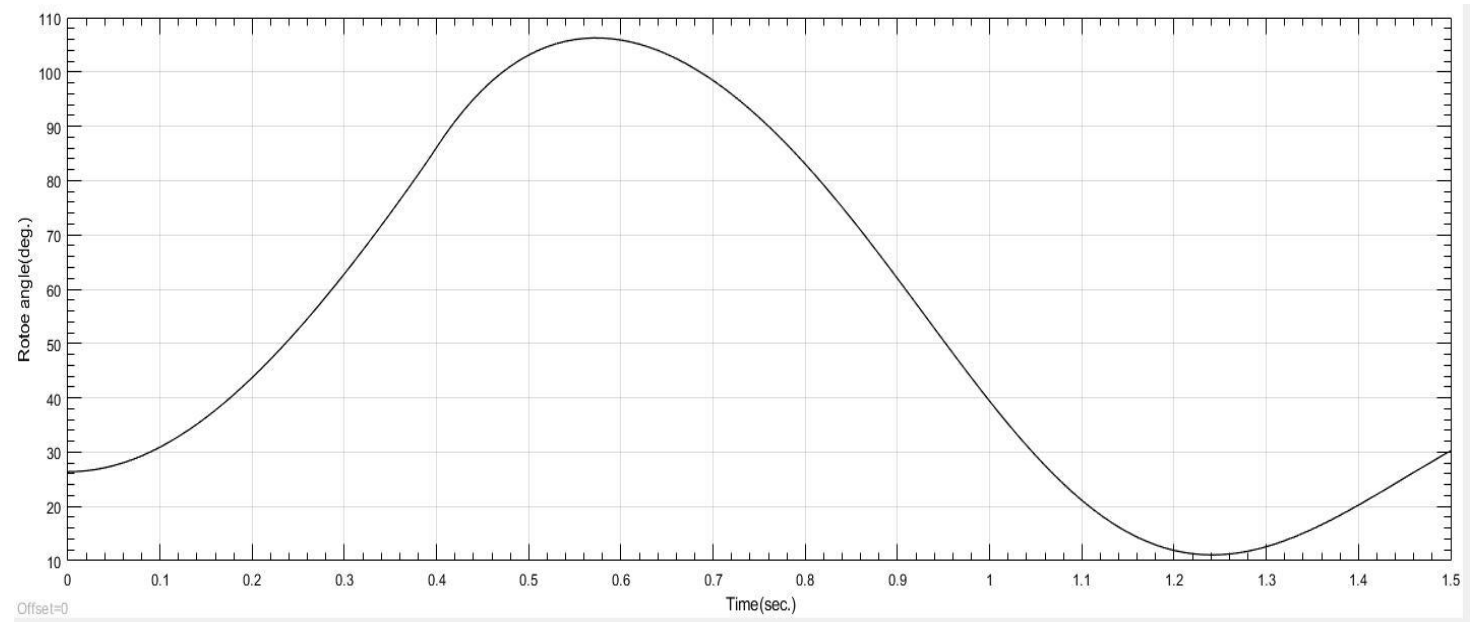

Figure 4c. Swing curve for power system (S1) at FCT=285 msec. with brake, (stable)

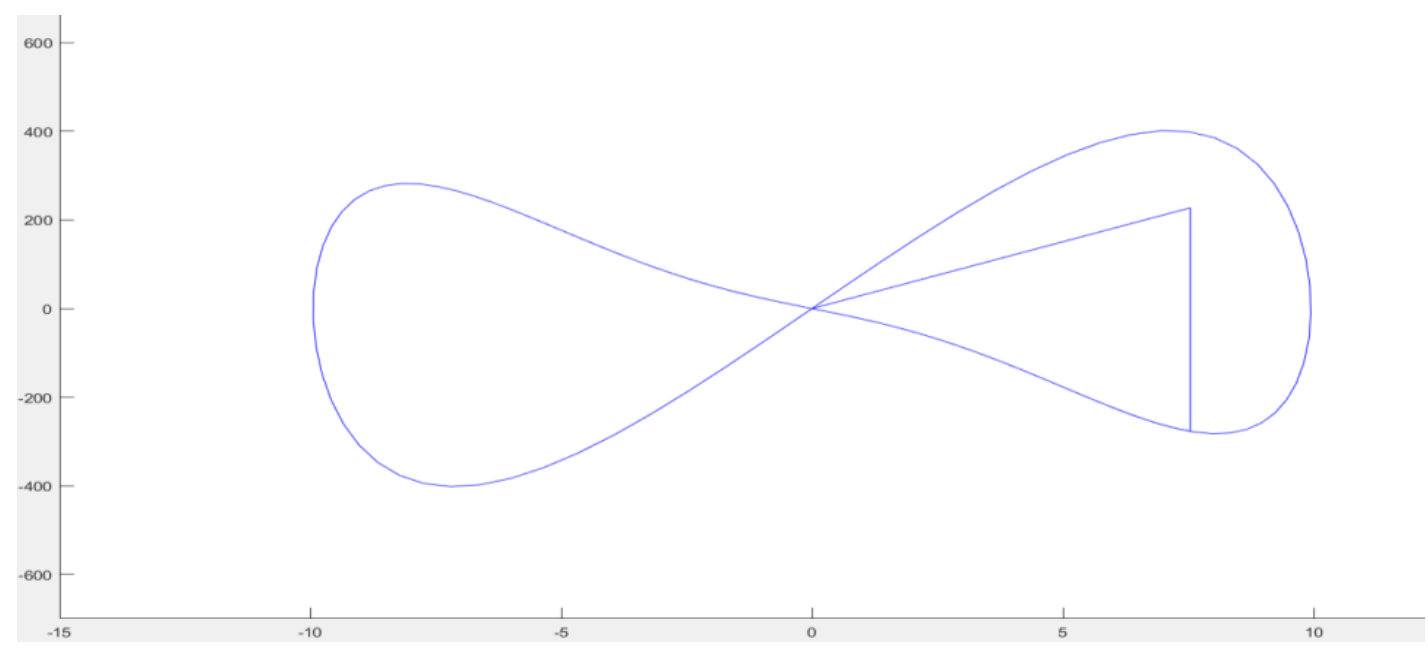

Figure 4d. RACKE versus disturbance angular velocity of S1 at FCT=240 msec. without brake (stable) 


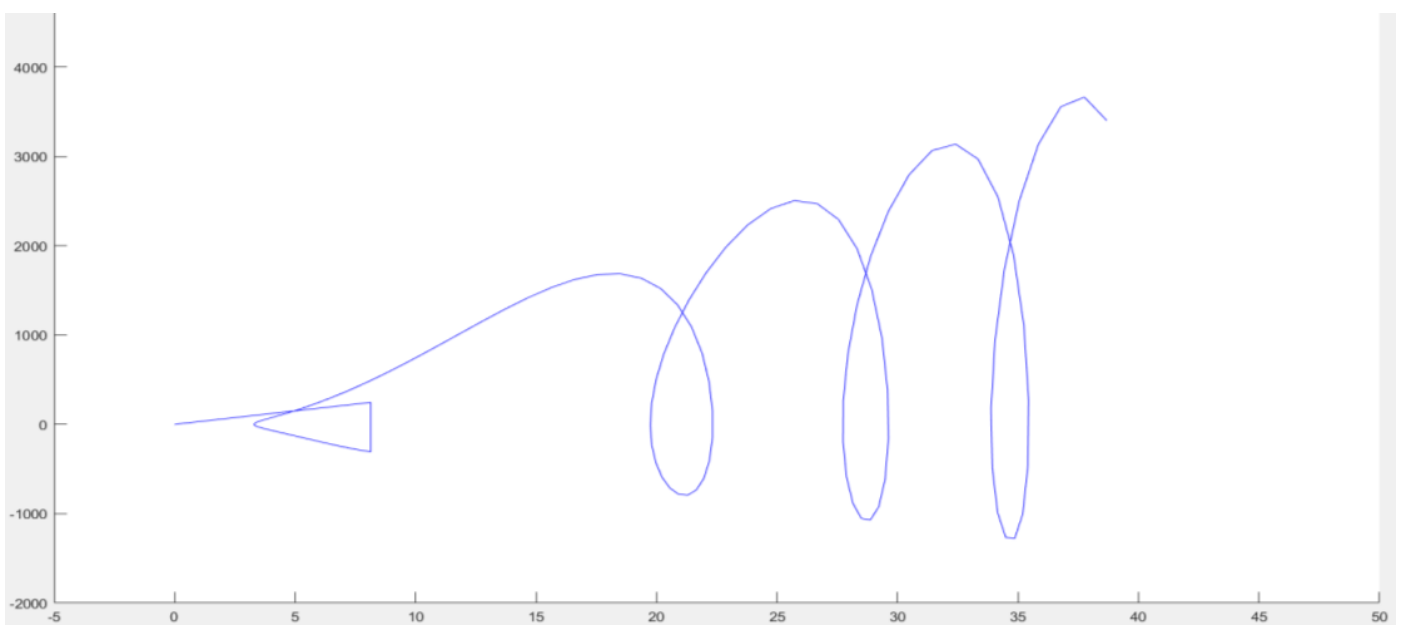

Figure 4e. RACKE versus disturbance angular velocity of S1 at FCT=285 msec. without brake (unstable)

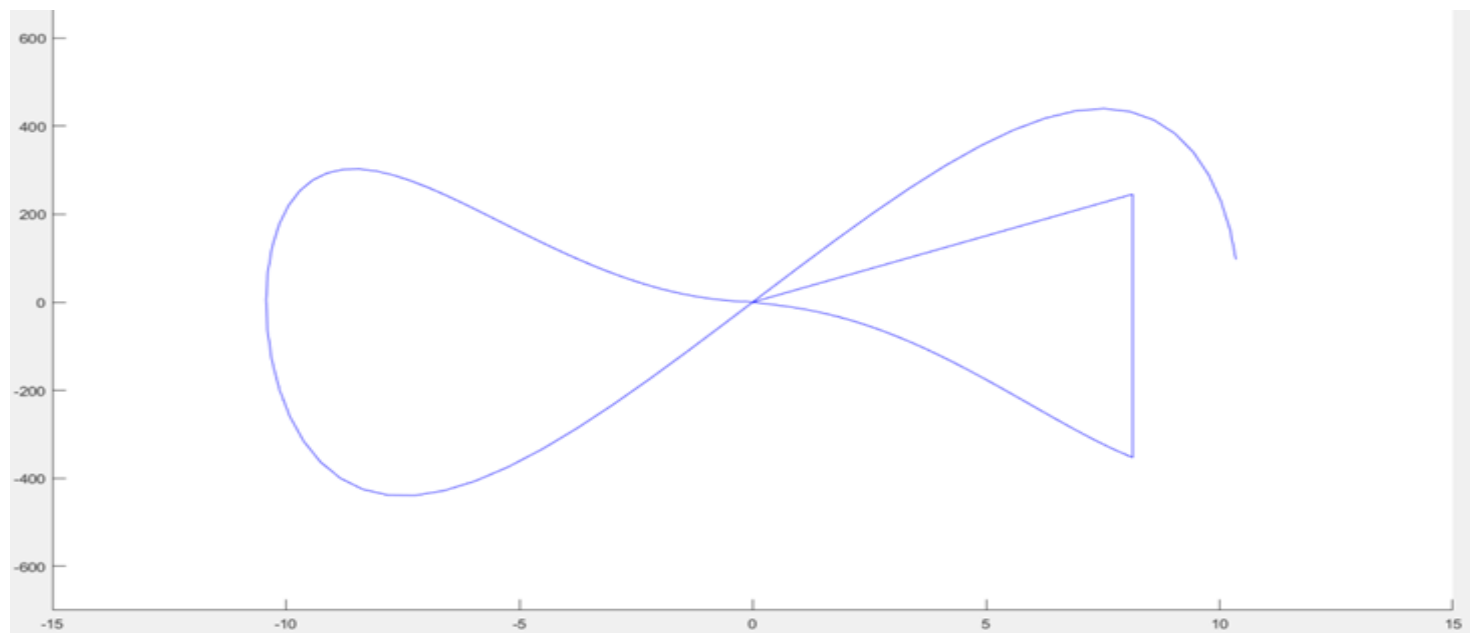

Figure 4f. RACKE versus disturbance angular velocity of S1 at FCT=285msec with brake (stable)

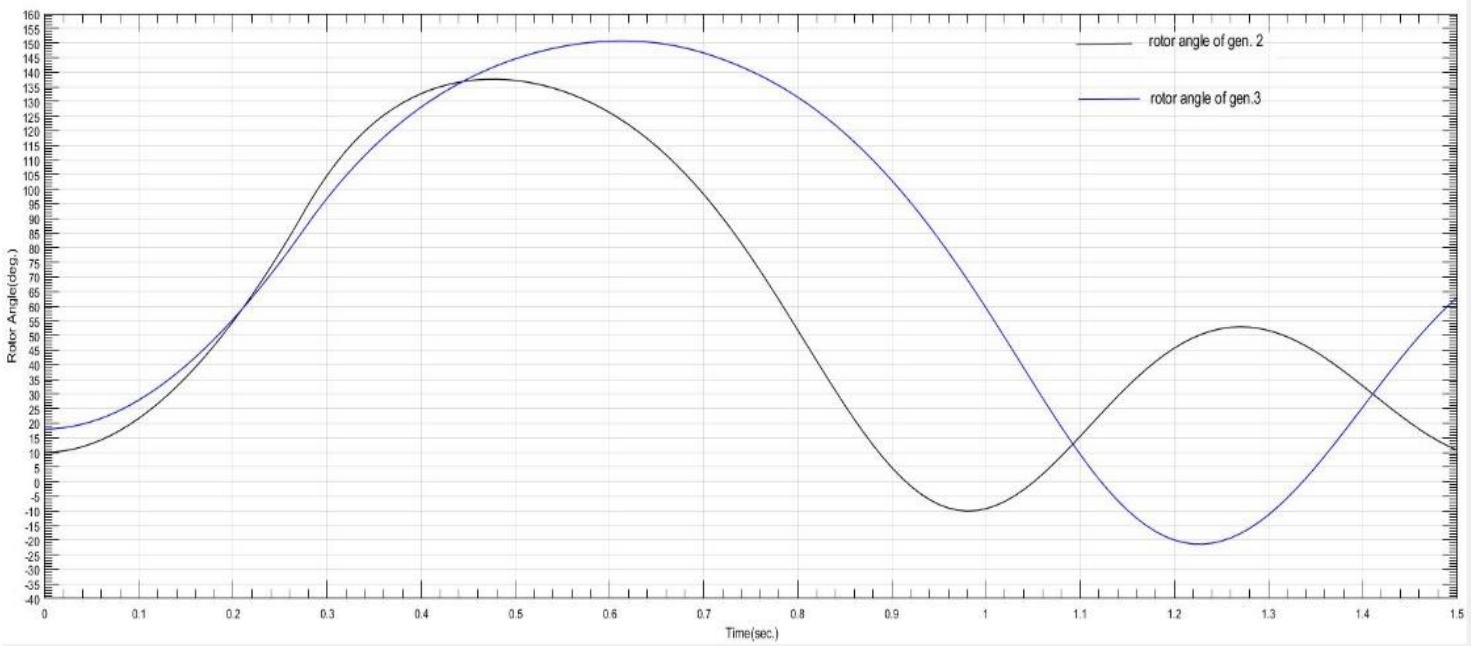

Figure 5a. Determination of TCC of (S2) at fault clearing=200 msec. (critical stable), without brake 


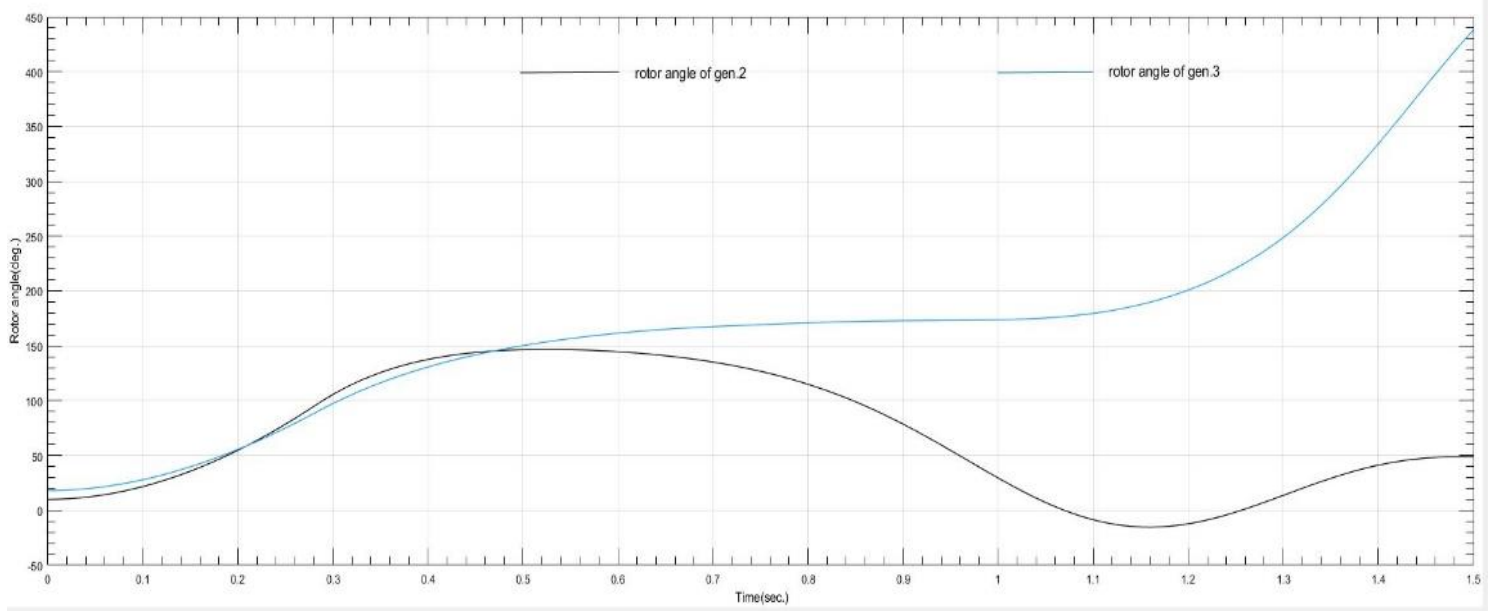

Figure 5b. Swing curve for power system (S2) at $202 \mathrm{msec}$. fault clearing, (unstable) without brake

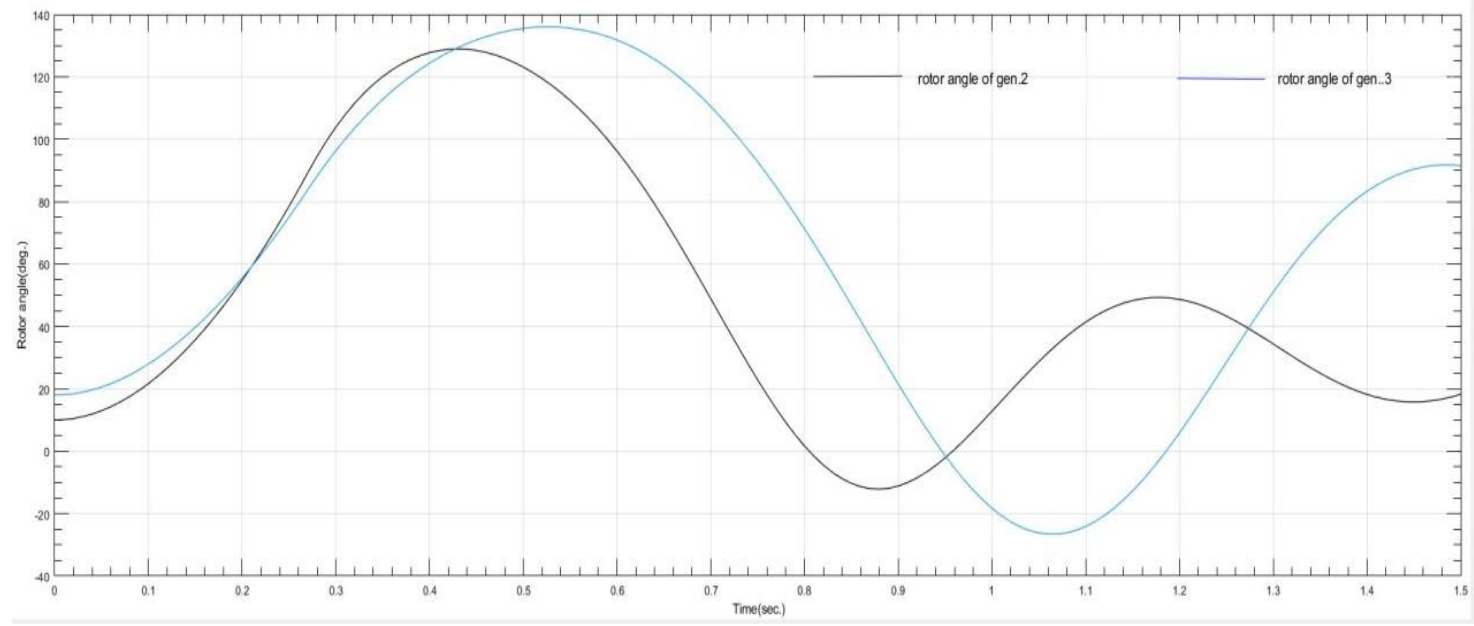

Figure 5c. Swing curve of (S2) at FCT=280 msec. with brake (stable)

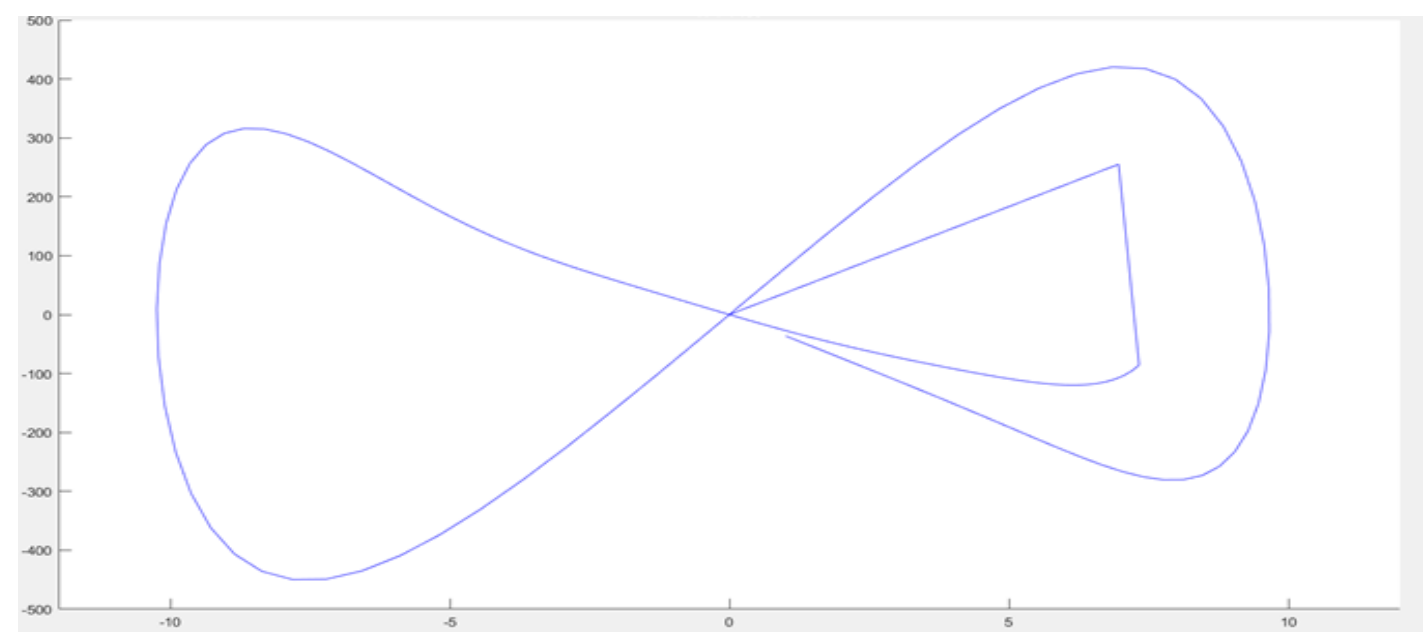

Figure 5d. RACKE versus disturbance angular velocity of S2 at CCT=200 msec. without brake (critical stable) 


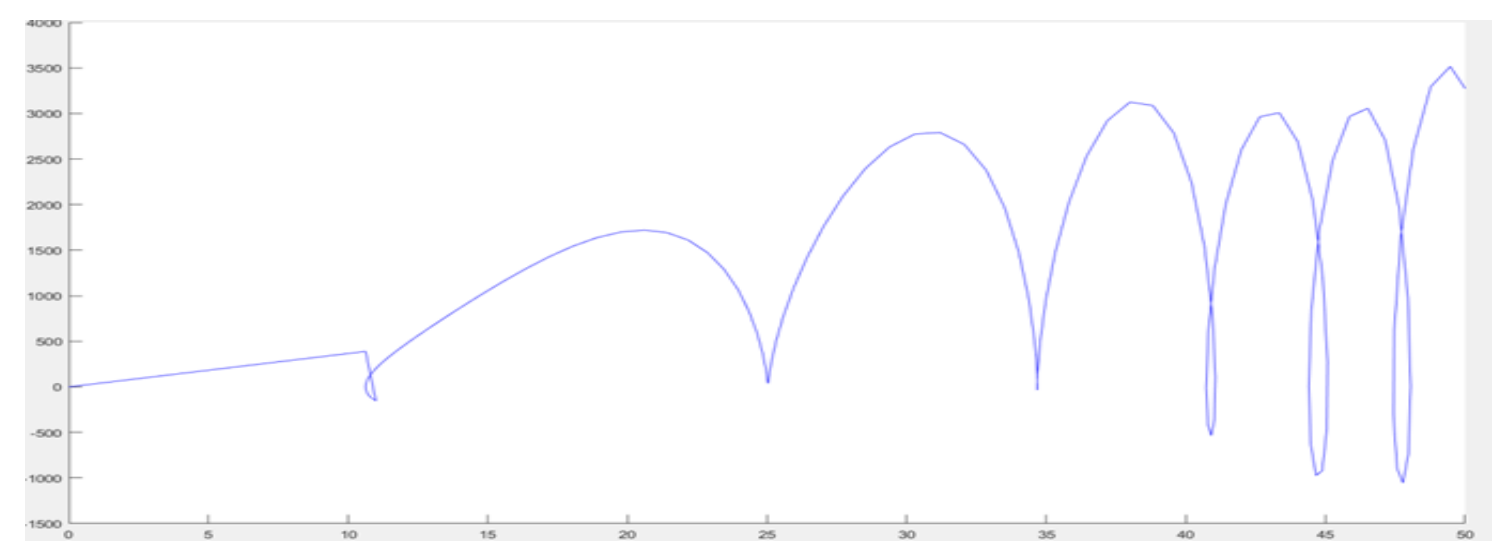

Figure 5e. RACKE versus disturbance angular velocity of S2at FCT=240 msec. without brake (unstable)

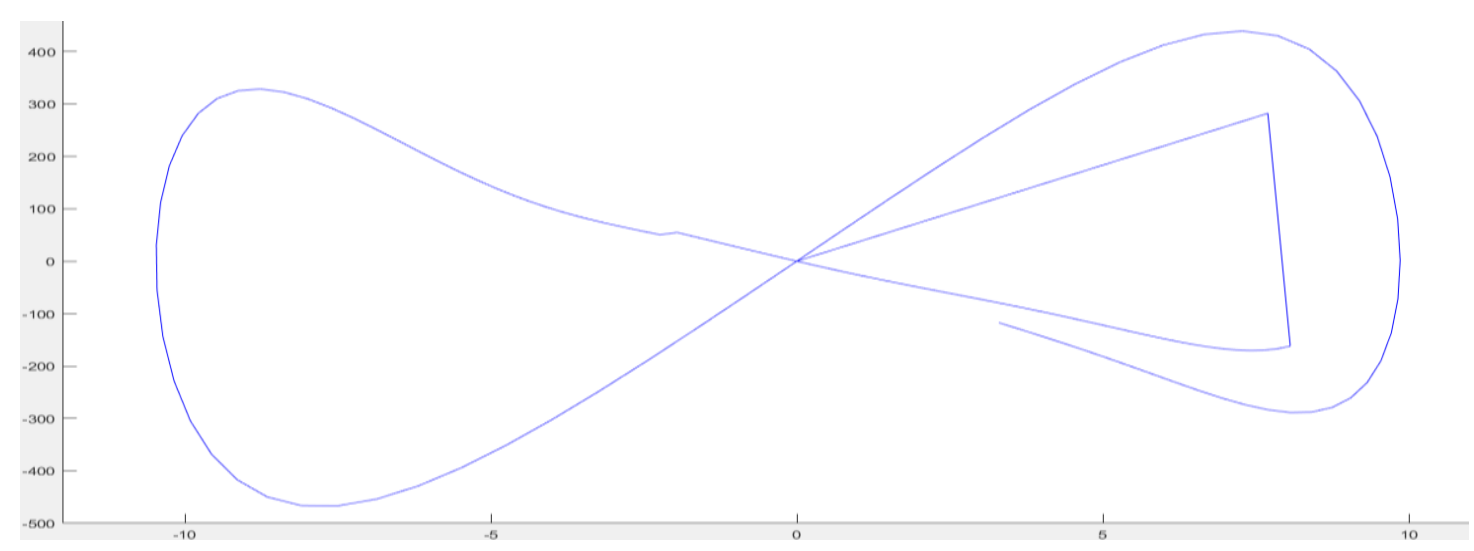

Figure 5f. RACKE against disturbance angular velocity of S2 at FCT= $240 \mathrm{msec}$. with brake, (stable)

\section{CONCLUSIONS}

RACKE method defined a certain instant of insertion and removal of the brake. The insertion of the brake should be achieved when RACKE of the critical machine reach its maximum negative value. Removal occurs when RACKE of the machine is zero and disturbance angular velocity passes through zero changing sign from positive to negative. One single machine and one multi-machine system are used to show the effect of dynamic braking on the behavior of the power system during emergency state, when RACKE criterion is used.

From the result obtained one can see that the strategy of RACKE method gives best damping of oscillation compared to indirect methods. In case of more than one machine may pull out of synchronism, the size of the brake applied at the terminals of the machine loosing synchronism has to be calculated using the admittance matrix technique, looking to the system from the terminals of that machine. The simulation shows that the applied of a braking resistor at the terminal of the machine pulling out of synchronism, simultaneously brings the system into stable trajectory. It is clear from the results obtained that using dynamic braking depending on the RACKE criterion for insertion and removal of the brake gives excellent results in comparison with other criteria used in this field.

\section{REFERENCES}

[1] R. Patel, T.S. Bhatti and D.P. Kothari, 2002. "MATLAB/Simulink-based transient stability analysis of a multimachine power system "International Journal Of Electrical Engineering Education, 39,4,3, pp. 320-335.

[2] M. A. Al-Taee, F. J. Al-Azzawi, A. A. Al-Taee and T. Z. Al-Jumaily, 2001. "Real-time assessment of power system transient stability using rate of change of kinetic energy method," IET Proceedings - Generation, Transmission and Distribution, vol.148, no. 6, pp. 505-510.

[3] Zaid H. Al-Tameemi, Hayder H. Enawi, Karrar M. Al-Anbary, Hussam M. Almukhtar, 2018. "Transient Stability Improvement of the Power Systems". Indonesian Journal of Electrical Engineering and Computer Science,12(3), pp. 916-923. 
[4] JIANG, H., DORSEY, J., and HABETLER, T., 1994.'Cost effective generator brake for improved generator transient response', IEEE Tvrins. Power Syst., 9, (4), pp. 184k-1846.

[5] OTA, H.; KITAYAMA, Y., ITO, H., FUKUSHIMA, N., MORITA, K., and KOKAI, K., 1996. 'Development of transient stability control system (TSC system) based on on-line stability. sedation', IEEE Truns. Power Syst., 11, (3), pp. 1463-1472.

[6] Saric, M., 2017. Generator dynamic response analysis and improvement following distribution network disturbance. Indonesian Journal of Electrical Engineering and Computer Science, 7(2), pp.356-363.

[7] Al-Azzawi F. J., Al-Taee M. A. and Al-Taee A.A., 1999. Online transient stability enhancement of power systems using rate of change of kinetic energy strategy, Proc. 3rd Int. Conf. on Computational Aspects and their Applications in Electrical Engineering (CATAEE'99), Amman, Jordan, 19-20 Oct., pp. 8-12.

[8] R. Zhang, Y. Xu, Z. Y. Dong, K. P. Wong, 2015. "Post-disturbance transient stability assessment of power systems by a self-adaptive intelligent system," IET Proceedings - Generation, Transmission, Distribution, vol. 9(3), pp. 296-305.

[9] Ali Hamzeh, Zakaria Al-Omari, 2019. Improved model for investigating transient stability in multimachine power systems, Indonesian Journal of Electrical Engineering and Computer Science, 13(1), pp. 368-376.

[10] Abha Tripathi, K. Uma Rao, L. Venkatesha, 2017. Multi-Machine Stability Using Dynamic Inversion Technique, International Journal of Electrical and Computer Engineering (IJECE), 7(6), pp. 3176-3189

[11] A. A. Al-Taee, M. A. Al-Taee, and W. Al-Nuaimy, 2016. "Augmentation of transient stability margin based on rapid assessment of rate of change of kinetic energy," Electric Power Systems Research, Elsevier, vol. 140, pp. 588-596.

[12] L. Kanagasabai, B. R. Reddy, and M. S. Kalavathi, 2013."Optimal power flow using ant colony search algorithm to evaluate load curtailment incorporating voltage stability margin criterion," International Journal of Electrical and Computer Engineering (IJECE), vol. 3, no. 5, pp. 603-611.

[13] A. A. Al-Taee, M. A. Al-Taee, and W. Al-Nuaimy, 2017."A speed Measurement Method for Fast Assessment of power system Transient Stability" 4th International Multi conference on system, Signal and Devices (SSD), IEEE, PP.366-371.

[14] K.R. Padiyar, S. Krishna, 2006. Online detection of loss of synchronism using energy function criterion, IEEE Trans. Power Deliv. 21 (1) 46-55.

[15] Arif S. J., Amu I. and Laskar S. H., 2005. Instantaneous angular speed measurement for low speed machines", Innovative Systems Design and Engineering, vol. 3(5), pp. 21 - 32.

[16] A. A. Al-Taee, M. A. Al-Taee, and W. Al-Nuaimy, 2017. "Fast Angular Speed Measurement Method for Online Transient Stability Assessment in power systems" IJETAS, V.1, No. 2, PP. 20 - 28.

[17] AL-AZZAWI. F.J. AL-WAFI. N.M... JASSIM. A.K. and OMAR, F., 1995. 'Braking resistor size, switching instants and assessment of power system transient stability by direct methods', IE (India) J., 76, pp. 175-181.

[18] M.L. SHELTON, W.A. METTELSTAD, P.F. WINKELMEN, W.J. BELLERBY, 1975. "Bonneville power administration $1400 \mathrm{MW}$ braking resistor". IEEE, Trans, Vol. PAS 94, pp. 602-611.

[19] A. SEN AND J. MEIES, 1978. "Augmentation of Transient Stability with braking resistor using optimal aim strategy" IEE Proc.Vol.125, PP 1249-1255.

[20] USMAN O. ALIYN AND A.H. EL-ABIAD, 1982"A local control strategy for power system in transient emergency state". IEEE Trans, Vol. 101, NO. 11, pp. 4245-4253.

[21] WILIAM A., 1968. MITTELSTAD "Four methods of power system damping". IEEE, Trans, Vol. 87, NO. 5, pp. 1323-1329.

[22] R. Patel, T.S. Bhatti, D.P. Kothari, 2003. Improvement of power system transient stability by coordinated operation of fast valving and braking resistor, IEE Gener.Transm. Distrib 150 (3) 311-316.

[23] Al-Azzawi F. J. and Omar F., 1989. Dynamic brake switching times in multi-machine power systems during emergency, Proc. 8th University Power Engineering Conf. (UPEC'89), Belfast, pp. 101-106.

[24] Mariotto L., Pinheiro H., Cardoso Jr. G.; Morais A. P., Muraro M. R., 2010. Power systems transient stability indices - an algorithm based on equivalent clusters of coherent generators, IET - Generation, Transmission, Distribution, vol. 4, (11), pp. 1223-1235.

[25] Al -Azzawi F. J., Al - Taee M. A. and Al-Jumaily T. Z., 2001. Microcomputer control of a dynamic brake using rate of change of kinetic energy strategy, Journal of Engineering and Technology, 20(3), pp. 11 -21.

\section{BIOGRAPHIES OF AUTHOR}

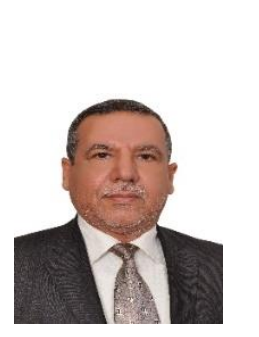

Majli Nema Hawas is presently Assistant Professor with Electrical Power Engineering Techniques Department at Electrical Engineering Technical college, Middle Technical University. He received the B.S., M.S and Ph.D. degrees from the university of Technology, Iraq, Baghdad. 